\title{
Controle e prevenção de pulgas em cães e gatos: análise das ações dos tutores
}

As pulgas são insetos achatados lateralmente, sem asas, pertencentes ao Filo Arthropoda, à classe Insecta e à ordem Siphonaptera. Na medicina veterinária, as pulgas são habitualmente encontradas em cães e gatos, porém, elas também vivem em uma variedade de outros animais domésticos e pequenos selvagens. A subespécie predominante que parasita cães e gatos é a Ctenocephalides felis felis, conhecida como pulga do gato, causando no animal ação irritativa e inflamatória, além de transmitir patógenos, onde estas causam perturbação e estresse aos animais, provocados pelas suas picadas e movimentos. A pesquisa foi realizada com tutores de animais de estimação, residentes em duas avenidas do Setor Pestana, em Guaraí Tocantins. A coleta de dados foi realizada através de questionários aplicados a todos os tutores de animais e continha seis perguntas fechadas de múltiplas escolhas. Acerca do questionário sobre o método de prevenção e controle de pulgas nos animais, foi constatado que $54 \%$ dos responsáveis utilizam medicamentos oriundos de farmácias. Com isso, conclui-se que prevalece o número de donos de animais que tem consciência dos danos a saúde que as pulgas podem causar a seus animais bem como o impacto econômico.

\section{Flea control and prevention in dogs and cats: analysis of guardian actions}

\begin{abstract}
The fleas are laterally flattened insects, without wings, belonging to the Filo Arthropoda, the Insecta class and the order Siphonaptera. In veterinary medicine, fleas are usually found in dogs and cats, however, they also live in a variety of other domestic and small wild animals. The predominant subspecies that parasite dogs and cats is the Ctenocephalides felis felis, known as Cat Flea, causing in the animal irriative and inflammatory action, besides transmitting pathogens, where they cause disturbance and stress to the animals, caused by their bites and movements. The research was carried out with pet tutors, residing in two avenues of the Pestana sector, in Guaraí Tocantins. Data collection was performed through questionnaires applied to all animal guardians and contained six closed questions of multiple choices. Regarding the questionnaire on the method of prevention and control of fleas in animals, it was found that $54 \%$ of the caregivers use medications from pharmacies. Thus, it is concluded that the number of pet owners who are aware of the health damage that fleas can cause to their animals and the economic impact prevails.
\end{abstract}

Keywords: Fleas; Tutors; Ctenocephalides felis felis.

\section{Topic: Parasitologia}

Reviewed anonymously in the process of blind peer.
Received: 08/03/2019

Approved: 14/05/2019

Karla Thaiza Silva Freitas (D)

Faculdade Guaraí, Brasil

http://lattes.cnpq.br/6155904150273264

http://orcid.org/0000-0003-3707-7506

karlathaisa.00@outlook.com

Jucyele Barbosa Barros (ib)

Faculdade Guaraí, Brasil

http://lattes.cnpq.br/7420113049480210

http://orcid.org/0000-0001-9248-2286

jullybarros06@outlook.com

Aluísio Vasconcelos de Carvalho (iD

Faculdade Guaraí, Brasil

http://lattes.cnpq.br/5200758055263996

http://orcid.org/0000-0002-3793-3133

aluisiovasconcelos@gmail.com

\section{Referencing this:}

FREITAS, K. T. S.; BARROS, J. B.; CARVALHO, A. V.. Controle e prevenção de pulgas em cães e gatos: análise das ações dos tutores. Agriculturae, v.1, n.1, p.13-20, 2019. DOI:

DOI: 10.6008/CBPC2674-645X.2019.001.0002 http://doi.org/10.6008/CBPC2674-645X.2019.001.0002 


\section{INTRODUÇÃO}

Muitos artrópodes vivem como ectoparasitos em cães e gatos, expondo estes animais a risco (GONZÁLEZ et al., 2004). Pode-se citar a espécie Ctenocephalides felis felis, um dos mais importantes ectoparasitos de cães e gatos no mundo inteiro, devido a sua distribuição geográfica atua como agente infestante e vetor de doenças, adquirindo resistência contra inseticidas comuns (LINARDI et al., 2012). A falta de controle desse inseto pode causar problemas para os animais dentre as patologias estão a dermatite, alergia, entre outros problemas (OLIVEIRA et al., 2008).

As pulgas são insetos achatados lateralmente, sem asas, pertencentes ao Filo Arthropoda, à classe Insecta e à ordem Siphonaptera (FORTES, 2004). Segundo Oliveira et al. (2008) estes insetos podem ser vistos a olho nu e não demonstram claramente as delimitações normais entre as partes do corpo (cabeça, tórax e abdômen) como a maioria dos insetos. Para Wilkinson et al. (1996), as pulgas são insetos ápteros, minúsculos, cor amarronzada e podem ser claramente visualizadas movendo-se frequentemente na pelagem, em alguns casos. São responsáveis pela transmissão de diversas doenças tanto nos humanos quanto nos animais acarretando diversas zoonoses, a exemplo da peste bubônica em humanos e dipilidíase em cães e gatos.

De acordo Vieira (2009) os entomologistas classificam as pulgas como seres universalistas, geralmente parasita de aves e mamíferos, comumente encontradas em todo o mundo. Na medicina veterinária, as pulgas são habitualmente encontradas em cães e gatos, porém elas também vivem em uma variedade de outros animais domésticos e pequenos selvagens (OLIVEIRA et al., 2008).

Para Vieira (2009) as espécies Ctenocephalides felis e C. canis, são os principais ectoparasitos de cães e gatos do mundo, sendo a subespécie predominante que parasita cães e gatos é a Ctenocephalides felis felis, conhecida como pulga do gato, causando no animal ação irritativa e inflamatória, além de transmitir patógenos.

No contexto urbano, a importância parasitológica desses insetos deve-se aos prejuízos causados como parasitos propriamente ditos, levando a irritação, prurido e dermatites alérgicas. Tais ações interferem diretamente na saúde humana e animal (DRYDEN et al., 1994). De acordo com Page (2008) a relação de proximidade que o Homem possui com animais contaminados aumenta o risco de transmissão com implicações na saúde pública em uma população humana mundial cada vez mais envelhecida, e crescentemente imunocomprometida.

Tanto na cidade quanto no campo, as pulgas causam um verdadeiro incômodo aos donos de animais de estimação, principalmente cães e gatos, pois suas picadas provocam surgimento de verminoses, anemias, alergias e dermatites. Visto isso, quem tem animais domésticos deve estar ciente da importância de mantêlos limpos para assim evitar o surgimento desses ectoparasitas (FERNANDES et al., 1996)

De acordo com Fortes (1997), as pulgas causam perturbação e estresse aos animais, provocados pelas suas picadas e movimentos. $O$ hospedeiro coça-se, esfrega-se em diversas superfícies e morde a pele com o intuito de livrar-se delas, produzindo lesões na pele que podem servir para invasão de bactérias e 
consequentemente uma infecção. $O$ animal infesta-se através do contato com outros animais parasitados ou por frequentar um ambiente infectado.

O animal pode se contaminar com pulgas ao percorrer ambientes contaminados, como parques, praças, onde outros animais infestados pelos ectoparasitas circulam. Outro meio de contaminação é o contato direto com outros animais infestados, sendo menos comum que o primeiro (BIRCHARD, 2008).

Em visto do apresentado, esta pesquisa objetivou-se determinar quais os métodos de prevenção e controle que os tutores de animais de estimação de cães e gatos utilizam para evitar a infestação de pulgas.

\section{METODOLOGIA}

Para o desenvolvimento do estudo, optou-se pela pesquisa quantitativa-qualitativa, por se tratar de um estudo que obteve coleta de dados e por demonstrar estatisticamente os resultados obtidos. A pesquisa foi realizada com tutores de animais de estimação residentes em duas avenidas do Setor Pestana, em Guaraí Tocantins. A região urbana de Guaraí é localizada nas seguintes coordenadas geográficas $8^{\circ} 50^{\prime} 03$ e $4^{\prime \prime} \mathrm{S}$ $48^{\circ} 30^{\prime} 52.8^{\prime \prime} \mathrm{W}$, e de acordo com o censo realizado em 2010, atualmente a cidade possui 23.200 habitantes e fica na região central do Estado do Tocantins a cerca de $172 \mathrm{~km}$ da capital do estado, Palmas.

A coleta de dados foi realizada através de questionários aplicados a todos os responsáveis e participantes da pesquisa. A metodologia escolhida, de acordo com Gil (2002), compreende-se que questionário é um conjunto de perguntas que são respondidas pelo alvo da pesquisa, e de acordo com Marconi et al. (1996), é um instrumento de coleta de dados através de uma série de questões ordenadas, respondido por escrito pelo pesquisado.

O questionário aplicado continha seis perguntas fechadas de múltiplas escolhas, facilitando a interpretação da pergunta e a análise dos dados coletados. Entre as questões contidas no questionário, uma delas perguntava se o responsável tinha conhecimento do risco que o animal corre ao estar infectado com pulga e qual o método comum utilizado por ele para o combate desses ectoparasitas.

Apresenta-se abaixo, no Quadro 1, as perguntas contidas na pesquisa com os tutores de animais das duas avenidas do setor Pestana em Guaraí (TO), que compreendia seis perguntas semiestruturadas, relacionadas com o método e prevenção utilizados pelos tutores para o combate de pulgas nos animais.

Quadro 1. Questões utilizadas no questionário aplicado aos tutores de animais sobre o combate e prevenção de pulgas.

\begin{tabular}{|l|}
\hline Qual seu animal de estimação? \\
\hline Você já observou em algum momento se seu animal tem infestação de pulgas \\
\hline Qual a frequência que você dar banho em seu animal? \\
\hline Qual o tratamento utilizado por você para combater as pulgas? \\
\hline Você tem consciência dos danos que as pulgas podem causar ao animal? \\
\hline $\begin{array}{l}\text { Tendo consciência que as pulgas infestam tanto os animais quanto o ambiente doméstico, quais as medidas de prevenção que } \\
\text { você utiliza para combatê-las }\end{array}$ \\
\hline
\end{tabular}

\section{RESULTADOS E DISCUSSÃO}

Realizou-se a aplicação do questionário em vinte e dois tutores de animais, com o intuito de se obter dados relacionados com a forma de combate e prevenção de pulgas em cães e gatos. Observou-se que há 
uma variação quanto a criação de cães e gatos representando $41 \%$ criam gatos, $41 \%$ criam cães e $18 \%$ criam ambas as espécies (Figura 1).



Figura 1: Descrição da quantidade de tutores que possuem gatos e cachorros em suas casas.

Os resultados podem se correlacionar com os dados do IBGE (2013), onde o Brasil encontra-se no ranking mundial na $2^{\circ}$ posição em números de animais de estimação como cães, gatos e aves. Restringindose os dados, encontra-se que 52,2 milhões de pessoas possuem cachorros e 22,1 milhões possuem gatos em suas residências.

O aumento considerável no mercado Pet tem favorecido a procura por animais de estimação devido a nova estruturação familiar, sobretudo pelo crescente número de pessoas que moram sozinhas, buscando a companhia de animais para suprimir essa carência (CARDOSO et al., 2016).

A partir da figura 2 pode-se perceber que $72 \%$ dos tutores de animais afirmam que seus animais estão ou já foram infestados por pulgas em algum momento de suas vidas. Resultados similares são encontrados no trabalho de Castro e Rafael (2006) em que dos 73 cães e 11 gatos examinados, $80 \%$ dos cães e $72 \%$ dos gatos estavam infestados por pulgas.

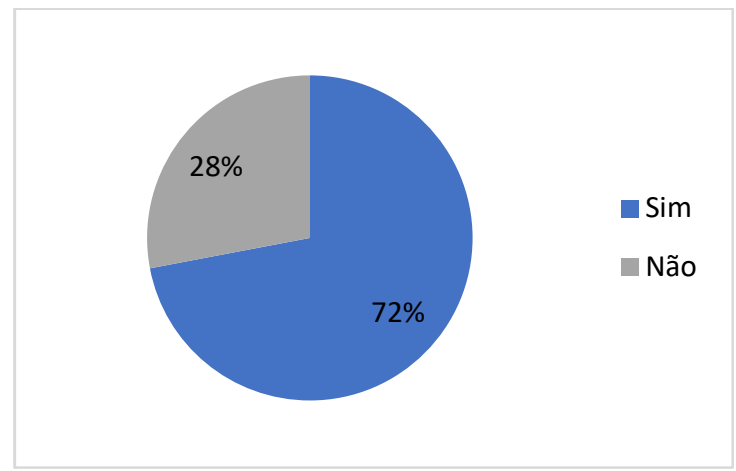

Figura 2: Questiona se em algum momento o animal já foi afetado por pulgas.

Moura (2008) também encontrou resultados parecidos, onde dos 220 cães pesquisados, 207 estavam infestados por pulgas e dos 52 gatos apreendidos, 38 estavam com infestação de ectoparasitas. As pessoas devem ter a consciência de que apenas $5 \%$ desses pequenos ectoparasitas estão no animal, boa parte da maioria está no ambiente que o animal está inserido ou que possui contato direto (FERNANDES et al., 1996).

Em virtude dos vários problemas causados pelas pulgas, muitos avanços científicos foram realizados na última década para atender a necessidade do controle e entender a biologia desse ectoparasita, atualmente o controle mais utilizado são os produtos químicos (VIEIRA, 2009). Perguntou-se aos tutores a 
frequência dos banhos dos animais, 18\% relataram que raramente seus pets tomam banho, $28 \%$ uma vez por semana e $54 \%$ duas vezes no mês (figura 3 ).

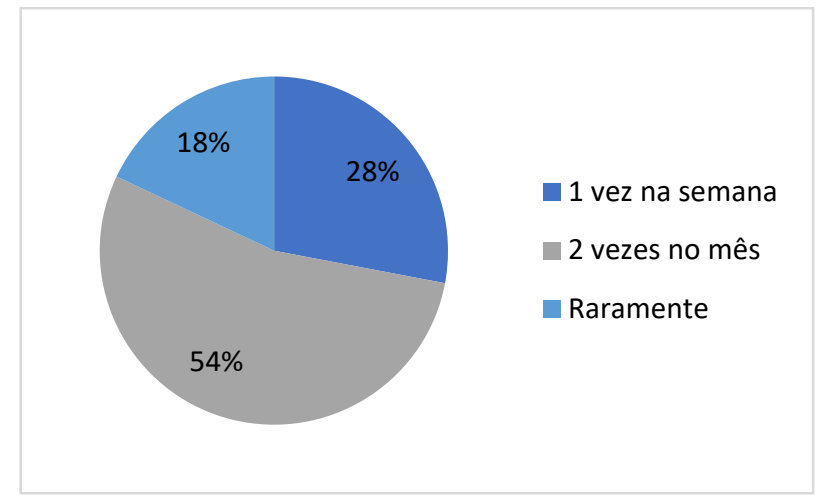

Figura 3: Questionamento acerca da frequência que os tutores costumam banhar seus animais.

No trabalho realizado por Cardoso et al., (2016) observou que $34,8 \%$ dos entrevistados que criavam cães relataram que no último mês deram banho no animal uma única vez, outros $26,1 \%$ deram o banho semanal e 15,2\% de animais que não tomaram banho, além disso, a pesquisa demonstrou que em relação aos gatos $57,89 \%$ não tomam banho.

De acordo com os mesmos autores, o ideal é que os animais tomem banho a cada sete dias no verão e no inverno a cada quinze dias. O banho realizado diariamente pode afetar a microbiota da pele e pelo do animal contribuindo para futuras infecções e possivelmente doenças oportunistas.

Sobre o uso de medicamentos para o controle e prevenção de pulgas, 6\% não utilizam nos animais, 13\% usam medicamentos veterinários, $27 \%$ remédios caseiros e $54 \%$ remédios oriundos de farmácias (Figura 4).

Recentemente encontram-se muitas medidas para o controle desse inseto como coleiras e inseticidas, necessitando ter o cuidado com reações alérgicas e/ou tóxica. Nos locais das picadas usar antibióticos, corticosteróides e anti-histamínicos. Além do mais, deve-se combater as pulgas também no ambiente já que a maior parte do seu ciclo de vida ocorre nele (LEITÃO et al., 1983).

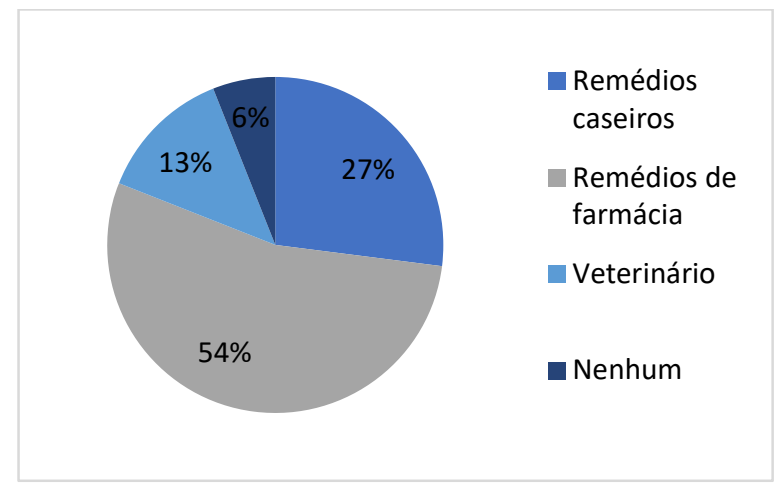

Figura 4: Questionamento acerca do tratamento utilizado pelos tutores quando seus animais estão infestados por pulgas.

Martín (1999) ressalta que o controle das pulgas deve ser feito por meio de integração para obter um efeito completo, por isso é necessário o tratamento no animal infestado, dos animais com os quais 
convivem o hospedeiro e o ambiente que está contaminado. Para o tratamento individual do animal recomenda-se utilizar inseticidas em spray, pulverizações no animal e no ambiente, assim como banhos associados com remédios e coleiras inseticidas, bastante úteis para o tratamento.

Segundo Griffin (1998), é importante o controle do ambiente interno porque os animais ficam a maior parte do tempo dentro das suas casas e este é o hábitat que pode ser mais efetivamente controlado. De acordo com Aiello et al. (2001) as infestações por pulgas no interior das casas podem ser facilmente controladas com inseticidas comuns ou inseticidas específicos.

Rohdich (2004) diz que remédios de farmácias e prescritos pelo veterinário possuem alta taxa de eficiência, pesticidas tópicos, como imidacloprida e fipronil garantem eficácia no controle do parasita por até um mês. Hnicilia (2011) complementa em tratar todos os animais acometidos com usos de spray, solução spot-on e comprimidos via oral em intervalos de 7 a 30 dias, são formas eficazes para o combate de pulgas em animais. Segundo Leitão et al. (1983) o uso de coleiras e inseticidas, assim como uso de antibióticos também ajudam no controle do ectoparasita.

Questionou-se sobre os métodos preventivos no combate a infestação de pulgas, destes, 68\% dos interlocutores ressaltaram o uso de remédios como alternativa preventiva, 18\% dedetizam o ambiente associado com a medicação no animal, 4\% apenas a dedetização, 9\% nenhuma das alternativas e nenhum dos tutores afirmaram usar outro método (Figura 5).

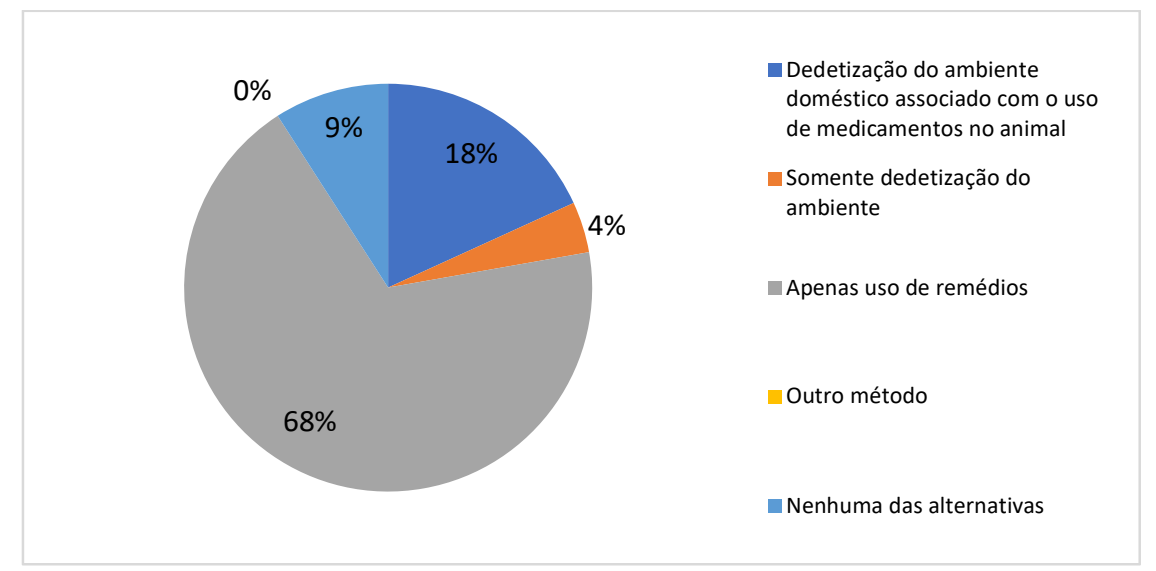

Figura 5: Questionamento sobre as medidas de prevenção utilizadas pelos tutores.

Segundo Aiello et al. (2001) para prevenir infestações transmitidas pelas pulgas é necessário a adoção de medidas físicas e químicas de controle, onde o controle não pode ser focado apenas nos animais. Cerca de $95 \%$ das pulgas e carrapatos estão presentes no ambiente e apenas $5 \%$ estão nos animais. Dessa forma, para conseguir sucesso na eliminação dos ectoparasitas, é importante a realização do controle ambiental juntamente com o controle no animal. O controle ambiental deve ser feito através da higienização local e da aplicação de inseticidas capazes de matar pulgas nas casinhas dos cães e gatos, frestas, paredes, pisos e ralos presentes. 


\section{CONCLUSÃO}

É evidente que a infestação por pulgas nos animais de estimação possa acontecer em algum estágio de vida do animal, é necessário que o tutor fique sempre alerta para evitar futuros constrangimentos ao animal e evidentemente ao dono.

O banho deve ser uma medida adotada pelo tutor como primeira ação para evitar patógenos e a disseminação doenças zoonóticas prevalentes na região. A prática, além de ser eficiente, garante o bemestar do animal e sua sanidade elevando o seu tempo de vida.

O uso de medicamentos, seja qual for, necessita de acompanhamento do veterinário para evitar a intoxicação do animal, o manejo inadequado do medicamento afetando outros animais e o ambiente, além dos prejuízos econômicos.

\section{REFERÊNCIAS}

AIELLO, B. S.; MAYS, A.. Manual Merck de veterinária. 8 ed. São Paulo: Roca, 2001

BIRCHARD, S. J.; SHERDING, R. G.. Manual Saunders de Clínica de pequenos animais. 3 ed. São Paulo: Roca, 2008.

CARDOSO, D. P.; SOUSA ESTRELA, D.; SARAIVA, L. A.; FARIAS, M. P. O.; SILVA, P. O.. Perfil dos tutores de cão e gato no município de Bom Jesus-PI. Pubvet, v.10, p.580-635, 2016.

CASTRO, M. C. M.; RAFAEL J. A.. Ectoparasitos de cães e gatos da cidade de Manaus, Amazonas, Brasil. Acta Amazonica, v.36, n.4, p.535-538, 2006.

DRYDEN, M.W.; RUST, M. K.. The cat flea: biology, ecology and control. Veterinary Parasitology, v.52, n.1, p. 1-19, 1994.

FERNANDES, C. G. N.; LINARDI, P. M.; FACCINI J. L. H.; MOURA, S. T.. Pulicideos de cães e gatos da cidade do Rio de Janeiro, (RJ, Brasil) e municípios vizinhos. Revista Universidade Rural: Ciência Vida, v.18, n.1-2, p.115- 118, 1996.

FORTES, E.. Parasitologia Veterinária. 4 ed. São Paulo: Ícone, 2004.

FORTES, E.. Parasitologia veterinária. 3 ed. São Paulo: Ícone, 1997.

GIL, A. C.. Como elaborar projetos de pesquisa. 4 ed. São Paulo: Atlas, 2002.

GONZÁLEZ, A.; CASTRO, D. C.; GONZÁLEZ, S.. Ectoparasitic species from Canis familiaris (Linné) in Buenos Aires province, Argentina. Veterinary Parasitology, v.120, n.1-2, p.123-129, 2004.

GRIFFIN, C. E.. Dermatite alérgica a pulgas. In: BIRCHARD, S. J.; SHERDING, R. G. Manual saunders: clínica de pequenos animais. 2 ed. São Paulo: Roca, 1998.

HNILICA, K. A.. Hypersensitivity disorders. In: HNILICA, K. A.. Small Animal Dermatology: A Color Atlas and Therapeutic Guide. 3 ed. Oxford: Elsevier Saunders, 2011.
IBGE. Instituto Brasileiro de Geografia e Estatística. População de animais de estimação no Brasil: 2013: em milhões. Rio de Janeiro: IBGE, 2013.

LINARDI, P. M.; SANTOS, J. L. C.. Ctenocephalides felis felis vs. Ctenocephalides canis: (Siphonaptera: Pulicidae): algumas questões para identificar corretamente estas espécies. Rev. Bras. Parasitol. Vet., Jaboticabal, v.21, n.4, p.345-354, 2012.

LEITÃO, J. L. S.; MEIRELES, J. A. F. S.. Doenças parasitárias do cão e gato. Portugal: Litexa, 1983.

MARTÍN, M. P.; DÍEZ, B. P.; DÍEZ, B. N.. Malofagidosis, Anopluridosis y Sifonapteridosis. In: CORDERO DEL CAMPILLO, M.; ROJO, F. A. V.; MARTÍNEZ, A. R. F. Parasitología Veterinaria. Madrid: Mc Graw Hill. 1999. p.719-724.

MARCONI, M. D. A.; LAKATOS, E. M.. Técnicas de pesquisa: planejamento e execução de pesquisas, amostragens e técnicas de pesquisas, elaboração, análise e interpretação de dados. 3 ed. São Paulo: Atlas, 1996.

MOURA, V. E.. Levantamento das espécies de pulgas em cães e gatos capturados no município de São Caetano do Sul-SP. Monografia (Especialização em Entomologia Urbana) - Universidade Estadual Paulista, São Paulo, 2008.

OLIVEIRA, A. C; MACHADO, J. A. C; ANTONIO, N. S.; NEVES. M. F.. Ctenocephalides canis e Ctenocephalides felis: Revisão de literatura. Revista Científica Eletrônica De Medicina Veterinária, v.6, n.11, 2008.

PAGE, S. W.. Antiparasitic drugs. In: MADDISON, J. E.; PAGE, S. W.; CHURCH, D. B.. Church, Small animal clinical pharmacology. 2 ed. Philadelphia: Saunders-Elsevier, 2008. p.198-260,

OHDICH, N.; ROEPKE, R. K. A.; ZSCHIESCHE, E.. A randomized, blinded, controlled and multi-centeres fiel study comparing the efficacy and safety of Bravecto ${ }^{\mathrm{TM}}$ (fluralaner) against Frontline $^{\mathrm{TM}}$ (fiproniel) in flea-and-tick infested dogs. Parasites \& Vectors, London, v.7, n. 83, p. 1-5, 2014. 
VIERIA, V. P. C.. Eficácia do Regulador de Crescimento de Artrópodes Fluazuron no Controle da Pulga

Ctenocephalides felis felis (Bouché, 1835) (Siphonaptera: Pulicidae) em Cães. Dissertação (Mestrado em

Concentração Parasitologia Veterinária) - Universidade Federal Rural do Rio de Janeiro, Seropédica, 2009.
WILKINSON, G. T.; HARVEY, R. G.. Dermatoses psicogênica. In: WILKINSON, G. T.; HARVEY, R. G.. Atlas colorido de dermatologia dos pequenos animais. 2 ed. São Paulo: Manole, 1996.

A CBPC - Companhia Brasileira de Produção Científica (CNPJ: 11.221.422/0001-03) detém os direitos materiais desta publicação. Os direitos referem-se à publicação do trabalho em qualquer parte do mundo, incluindo os direitos às renovações, expansões e disseminações da contribuição, bem como outros direitos subsidiários. Todos os trabalhos publicados eletronicamente poderão posteriormente ser publicados em coletâneas impressas sob coordenação da Cognitionis Publishing, da Companhia Brasileira de Produção Científica e seus parceiros autorizados. Os (as) autores (as) preservam os direitos autorais, mas não têm permissão para a publicação da contribuição em outro meio, impresso ou digital, em português ou em tradução. 